Discussão e conclusões: Uma historia clínica e exame objetivo detalhado são essenciais no diagnóstico. A Ortopantomografia, Ecografia de partes moles e a Tomografia Computorizada desempenham um papel importante na deteção dos cálculos e determinação da sua localização, a última apresenta uma elevada sensibilidade. As manifestações de sialolitíase na população pediátrica são diferentes das dos adultos em alguns aspetos: menor duração dos sintomas obstrutivos e presença de cálculos de menores dimensões e localizados mais distalmente. Os tratamentos conservadores são os mais populares na população pediátrica do qual se destaca a sialoendoscopia. Dependendo da localização e dimensões pode ser necessário abordagem extra-oral, que envolve remoção da glândula atingida.

http://doi.org/10.24873/j.rpemd.2017.12.047

\section{\#015 Reabilitação Estética e Funcional da Zona Anterior com recurso a Resinas Compostas}

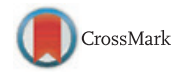

Rita Bornes*, Andreia Façanha, Carlos Almeida, Rute Rio, António Capelas

Universidade Católica Portuguesa

Introdução: A harmonia do sorriso é marcada pelo equilíbrio entre dentes, a proporção com a gengiva, lábios e rosto. Este caso apresenta uma alternativa conservadora para a reabilitação de dentes extensamente restaurados e com espigão perdido. O método escolhido foi a técnica restauradora adesiva direta com estratificação de resinas compostas.

Descrição do caso clínico: Paciente do género feminino, 57 anos de idade, procurou a Clínica Dentária Universitária da UCP, relatando insatisfação com a aparência estética do seu sorriso. Após avaliação clínica, constatou-se presença de múltiplas restaurações sobrepostas pigmentadas, diastema e coroa do 2.2 perdida. Realizou-se status fotográfico e radiográfico, elaborou-se enceramento de diagnóstico e posterior mock-up. Para a seleção das cores da resina composta a ser utilizada foram colocados pequenos incrementos de resina fotopolimerizada sobre a superfície dentária. Foi selecionada a cor do sistema HRI da Micerium: UD3,5 em cervical, UD3 no terço médio, OBN para o esmalte palatino e incisal, OW para a última camada de esmalte vestibular e um opacicificador (IM) nos dentes 1.3 e 2.1. Após o acabamento, com discos abrasivos de diferentes granulações por ordem decrescente foi obtido o polimento. Em consulta de controlo foram aprimorados os acabamentos e para o polimento foi utilizada escova de pêlo de crina de cabra, e pastas de polimento conferindo o brilho final.

Discussão e conclusões: Com a evolução dos sistemas adesivos e das resinas compostas é atualmente possível conceber restaurações diretas esteticamente aceitáveis com preservação de estrutura dentária e com baixo custo associado. Para obter sucesso em restaurações de dentes anteriores o planeamento estético é crucial. Nessa etapa, as propriedades óticas e a dinâmica de luz das estruturas dentárias necessitam ser reconhecidas para a caracterização da opalescência, translucidez, opacidade, textura superficial e cor - incluindo matiz, croma e valor. Esse conhecimento sobre a caracterização permitirá a estratificação correta dos incrementos de resina com- posta na restauração dentária, resultando numa aparência natural. Com o planeamento adequado, enceramento e estratificação foi possível restabelecer o sorriso com proporções, forma e naturalidade bastante satisfatórias.

http://doi.org/10.24873/j.rpemd.2017.12.048

\#016 Um caso de uma férula dentária em ouro numa freira clarissa do século XV

Isabel Poiares Baptista*, Catarina Leal, Miguel Munhós, Eugénia Cunha

Direção Regional da Cultura do Centro - Coimbra, Área de Medicina Dentária - Faculdade de Medicina, Universidade de Coimbra, Centro de Ecologia Funcional, Laboratório de Antropologia Forense, Departamento das Ciências da Vida

Introdução: Relata-se a descoberta de uma ligadura dentária de ouro, durante a exumação de um esqueleto pertencente a uma freira do final do século XV, no Convento de Santa Clara-a-Velha, em Coimbra

Descrição do caso clínico: O crânio bem preservado de uma freira medieval apresenta o incisivo lateral superior esquerdo ferulizado ao canino por uma ligadura de ouro. Os restantes incisivos superiores foram perdidos antemortem, provavelmente devido a doença periodontal avançada. Entre os dentes remanescentes, os incisivos inferiores e os molares superiores apresentam uma perda óssea severa, e os pré-molares apresentam lesões de cárie. No exame radiográfico identificaram-se ainda uma lesão apical num incisivo inferior e imagens de osteíte e de inclusão de resto radicular.

Discussão e conclusões: A datação por carbono radioativo coincide com a análise semi-quantitativa efectuada à estrutura metálica, identificando como proveniente do final do século XV. Este convento está associado à classe média medieval, bem conhecido pelo consumo de altos níveis de açúcar. Da observação dos 68 corpos exumados, verificou-se uma maior prevalência de cáries em comparação com outras amostras esqueléticas portuguesas do mesmo período, bem como uma alta prevalência de doença periodontal, sendo esta férula um caso único. Este caso, pela boa preservação dos ossos do crânio, representa uma descrição pormenorizada e rara de uma periodontite severa em amostras esqueléticas da idade média da Península Ibérica. Afigura-se igualmente como uma das primeiras evidências de tratamentos dentários da idade média na Europa.

http://doi.org/10.24873/j.rpemd.2017.12.049

\section{\#017 Gengivectomia sob sedação consciente - caso clínico}

Ana Boyé de Sousa*, Ricardo Grazina, Manuela Carrilho, Conceição Sepúlveda, Francisco Marques, Gisela Costa

\section{Centro Hospitalar e Universitário de Coimbra}

Introdução: Desde 1997 que o Serviço de Estomatologia em conjunto com o Serviço de Anestesiologia do Centro Hospitalar e Universitário de Coimbra implementou a consulta de seda- 